Motrivivência Ano XXI, No 32/33, P. 104-125 Jun-Dez./2009

\title{
OS MEGAEVENTOS ESPORTIVOS \\ E SEUS IMPACTOS: o caso das Olimpíadas da China ${ }^{1}$
}

Ricardo Ricci Uvinha²

\section{Resumo Abstract}

A presente década apresenta ao

Brasil a possibilidade de realização de dois expressivos megaeventos esportivos: a Copa do Mundo de 2014 e as Olimpíadas de Verão de 2016. Entende-se a partir daí fundamental compreender os possíveis impactos nas cidades-sede, em especial nos setores de lazer, esporte e turismo. O texto utilizará como caso dos XXIX Jogos Olímpicos de Verão em Beijing, China, explorando seus significados e levando em consideração o valioso exemplo ocorrido no âmbito daquela cultura

This decade has in Brazil the ability to carry out two significant sporting mega events: the 2014 World Cup and the Olympics in summer 2016. It is understood from then essential to understand the possible impacts on host cities, particularly in the sectors of leisure, sport and tourism. The text used as the case of the XXIX Summer Olympics in Beijing, China, exploring their meanings and taking into consideration the valuable example that occurred in ancient culture, even if it is a reality appa-

1 Artigo formulado com base no capítulo produzido para o livro "Megaeventos Esportivos e Cidades Olímpicas" (UFRGS, no prelo), que por sua vez é parte integrante de tese de livre-docência defendida na Universidade de São Paulo, USP (UVINHA, 2008).

2 Mestre em Educação Física (Estudos do Lazer) pela FEF/UNICAMP e Doutor em Ciências da Comunicação (Turismo e Lazer) pela ECA/USP. Professor Livre-docente da Escola de Artes, Ciências e Humanidades da Universidade de São Paulo - EACH/USP. Líder do Grupo Interdisciplinar de Estudos do Lazer da Universidade de São Paulo - GIEL/USP/CNPq. Contato: uvinha@usp.br 
milenar, mesmo que se trate de uma realidade aparentemente tão dispare da brasileira mesmo em dias que vivemos sob a égide da globalização.

Palavras-chave: Megaeventos esportivos; China. Lazer e Turismo. rently so shoot the Brazilian even on days that we live under the aegis of globalization.

Keywords: Sports mega-events; China; Recreation and Tourism.

\section{Introdução}

A presente década apresenta ao Brasil a possibilidade de realização de dois expressivos megaeventos esportivos: a Copa do Mundo de 2014 e as Olimpíadas de Verão de 2016. No caso da Copa do Mundo, será a segunda vez que o evento será realizado no Brasil, ao passo que as Olimpíadas impõem um desafio inédito para a América do Sul.

A despeito do reconhecido bônus que tais eventos inferem em suas cidades-sede, será questionado nesse artigo sobre o ônus presente em tais candidaturas, em especial a Olímpica: quais são os possíveis impactos nas cidades-sede? Qual a garantia de retorno a partir de uma exorbitância de investimentos (em geral públicos) destinado aos mesmos? Qual a real proximidade de eventos identificados como poderosos veículos de marketing, mostrando-se capazes de dar forma e satisfazer às demandas de mercados globais, com a identidade esportiva do país?

Para permitir tal discussão, será adotado como caso a realização dos XXIX Jogos Olímpicos de Verão em Beijing, China, evidenciando características associadas à realização do mesmo e refletindo elementos atrelados a uma "Educação Olímpica" promovida, em especial, na realidade cotidiana da população chinesa.

\section{O Global e o Local nas Olim- píadas da China}

Entende-se fundamental abordar a Olimpíada da China a luz da discussão que se coloca aqui sobre a abertura de um país para o mundo numa sociedade em vias de globalização. É bem provável afirmar que toda a preparação para o evento e a realização do mesmo trouxe significativas influências no desenvolvimento dos setores do lazer, turismo, esportes e educação no país. Por outro lado, uma série de inferências podem ser efetuadas sobre o impacto negativo desse megaevento no país, em que pese a subtilização posterior dos grandes 
Ano XXI, $n^{\circ} 32 / 33$, junho e dezembro/2009

equipamentos esportivos bem como sua direta influência nos hábitos de um povo com tradição milenar.

Os Jogos Olímpicos de Verão ou Olimpíadas Modernas ${ }^{3}$, nomeado simplesmente de Olimpíadas e que se diferenciam dos Jogos Olímpicos de Inverno ${ }^{4}$, teve sua retomada em 1896 na cidade de Atenas com o barão francês Pierre de Coubertin como um dos proponentes. O evento ocorre a cada quatro anos desde então, exceto por algumas interrupções como nas guerras mundiais:

\section{QUADRO 1 - Jogos Olímpicos de Verão}

\begin{tabular}{|l|l|l|}
\hline Ano & \multicolumn{1}{|c|}{ Evento } & \multicolumn{1}{c|}{ Local } \\
\hline 1896 & I Olimpíada & Atenas, Grécia \\
\hline 1900 & II Olimpíada & Paris, França \\
\hline 1904 & III Olimpíada & Sant Louis, Estados Unidos \\
\hline 1906 & Edição comemorativa & Atenas, Grécia \\
\hline 1908 & IV Olimpíada & Londres, Reino Unido \\
\hline 1912 & V Olimpíada & Estocolmo, Suécia \\
\hline 1916 & VI Olimpíada & Não realizada \\
\hline 1920 & VII Olimpíada & Antuérpia, Bélgica \\
\hline 1924 & VIII Olimpíada & Paris, França \\
\hline 1928 & IX Olimpíada & Amsterdã, Holanda \\
\hline 1932 & X Olimpíada & Los Angeles, Estados Unidos \\
\hline 1936 & XI Olimpíada & Berlim, Alemanha \\
\hline 1940 & XII Olimpíada & Não realizada \\
\hline 1944 & XIII Olimpíada & Não realizada \\
\hline 1948 & XIV Olimpíada & Londres, Reino Unido \\
\hline 1952 & XV Olimpíada & Helsinque, Finlândia \\
\hline 1956 & XVI Olimpíada & Melbourne, Austrália/Estocolmo, Suécia ${ }^{1}$ \\
\hline
\end{tabular}

3 As Olímpiadas consideradas "ancestrais" datam de 776 a.C em Olímpia, Grécia, e também eram realizadas a cada quatro anos. Reunia em seu contexto um número menor de modalidades e era dirigida apenas a homens gregos (IOC, 2008).

4 Os Jogos Olímpicos de Inverno ocorrem desde 1924 em Chamonix, França, e também são realizados a cada quatro anos. Reúnem-se no evento provas executadas no gelo ou neve, como esqui alpino, patinação artística e de velocidade e hóquei no gelo. Ocorreu por duas vezes na Ásia, ambas no Japão, em Sapporo 1972 e Nagano 1998 (IOC, 2008). 


\begin{tabular}{|l|l|l|}
\hline Ano & \multicolumn{1}{|c|}{ Evento } & \multicolumn{1}{c|}{ Local } \\
\hline 1960 & XVII Olimpíada & Roma, Itália \\
\hline 1964 & XVIII Olimpíada & Tóquio, Japão \\
\hline 1968 & XIX Olimpíada & Cidade do México, México \\
\hline 1972 & XX Olimpíada & Munique, Alemanha Ocidental \\
\hline 1976 & XXI Olimpíada & Montreal, Canadá \\
\hline 1980 & XXII Olimpíada & Moscou, União Soviética \\
\hline 1984 & XXIII Olimpíada & Los Angeles, Estados Unidos \\
\hline 1988 & XXIV Olimpíada & Seul, Coréia do Sul \\
\hline 1992 & XXV Olimpíada & Barcelona, Espanha \\
\hline 1996 & XXVI Olimpíada & Atlanta, Estados Unidos \\
\hline 2000 & XXVII Olimpíada & Sydney, Austrália \\
\hline 2004 & XXVIII Olimpíada & Atenas, Grécia \\
\hline 2008 & XXIX Olimpíada & Beijing, China \\
\hline 2012 & XXX Olimpíada & Londres, Reino Unido \\
\hline & & \\
\hline
\end{tabular}

Fonte: Adaptado de IOC (2008)

Como é possível apreender do quadro anterior, as Olimpíadas ocorreram apenas duas vezes em solo asiático, em Tóquio 1964 e Seul em 1988, antes de sua $29^{a}$ edição em Beijing.

Morris (2004) lembra que em 1907 o staff da Tianjin Young Men's Christian Association lançou um desafio à sociedade chinesa, formulando três provocativas questões:

a) quando a China estará apta para enviar um atleta para uma Olimpíada?

b) quando a China estará apta para ganhar a primeira medalha de ouro?

c) quando a China estará apta a convidar todo o mundo para vir a Beijing numa Olimpíada?
É possível saber nos dias atuais que a primeira participação de um atleta chinês no evento ocorreu nas Olimpíadas de Los Angeles em 1932, que a China foi conquistar sua primeira medalha de ouro também em Los Angeles porém nas Olimpíadas de 1984, e que finalmente em 2008 se deu a resposta do desafio 3 . Vejamos descritivo sobre o histórico da participação chinesa em Olimpíadas no quadro que segue: 
Ano XXI, n 32/33, junho e dezembro/2009

\section{QUADRO 2 - Histórico da participação da China nas Olimpíadas}

\begin{tabular}{|c|c|}
\hline Ano & Fato \\
\hline 1922 & $\begin{array}{l}\text { Eleito o primeiro membro do IOC de } \\
\text { nacionalidade chinesa: Wang Zhengting. }\end{array}$ \\
\hline 1928 & $\begin{array}{l}\text { Song Ruhai participou dos Jogos Olímpicos } \\
\text { de Amsterdã como observador enviado pelo } \\
\text { governo chinês. }\end{array}$ \\
\hline 1932 & $\begin{array}{l}\text { O velocista Liu Changchun participou dos Jogos } \\
\text { Olímpicos de Los Angeles como o primeiro } \\
\text { atleta chinês no evento. }\end{array}$ \\
\hline 1939 & $\begin{array}{l}\text { Kong Xiangxi foi eleito membro do IOC na } 39^{a} \\
\text { sessão plenária que ocorreu em Londres, Reino } \\
\text { Unido. }\end{array}$ \\
\hline 1947 & $\begin{array}{l}\text { Dong Shouyi foi eleito membro do IOC na } 41^{\text {a }} \\
\text { sessão plenária realizada em Estocolmo, Suécia. }\end{array}$ \\
\hline 1948 & $\begin{array}{l}33 \text { esportistas masculinos chineses participaram das } \\
\text { competições de basquete, futebol, atletismo, natação } \\
\text { e ciclismo nos Jogos Olímpicos de Londres. }\end{array}$ \\
\hline 1952 & $\begin{array}{l}\text { A China enviou uma delegação de } 40 \text { membros } \\
\text { aos Jogos Olímpicos de Helsinque, mas apenas } \\
\text { Wu Chuanyu conseguiu participar das provas } \\
\text { preliminares de } 100 \text { metros de natação costas, } \\
\text { já que o evento esportivo estava terminando } \\
\text { quando a delegação chinesa chegou ao destino. }\end{array}$ \\
\hline 1956 & $\begin{array}{l}\text { AComissãoEsportiva Nacional daChinadeclarou } \\
\text { que abandonava os } 16^{\circ} \text { Jogos Olímpicos. Taipei } \\
\text { enviou } 21 \text { esportistas masculinos para competir } \\
\text { no atletismo, levantamento de pesos, tiros, } \\
\text { basquete e boxe. }\end{array}$ \\
\hline 1958 & $\begin{array}{l}\text { O Comitê Olímpico Chinês declarou sua retirada } \\
\text { do IOC em protesto contra a aplicação da política } \\
\text { de "duas Chinas" por parte de alguns países. }\end{array}$ \\
\hline
\end{tabular}




\begin{tabular}{|c|c|}
\hline Ano & Fato \\
\hline 1960 & $\begin{array}{l}47 \text { atletas de Taipeiparticiparam das competições } \\
\text { de atletismo, natação, tiros, futebol, basquete } \\
\text { e boxe nos Jogos Olímpicos de Roma. Yang } \\
\text { Chuanguang conseguiu a medalha de prata no } \\
\text { decatlo, a primeira medalha olímpica da China } \\
\text { na história. }\end{array}$ \\
\hline 1964 & $\begin{array}{l}\text { Um total de } 55 \text { atletas de Taipei participaram } \\
\text { dos } 18^{\circ} \text { Jogos Olímpicos de Tóquio. }\end{array}$ \\
\hline 1968 & $\begin{array}{l}43 \text { esportistas de Taipei participaram dos Jogos } \\
\text { Olímpicos da Cidade do México. Ji Zheng } \\
\text { conquistou o terceiro posto na final dos } 80 \\
\text { metros com barreira feminino. }\end{array}$ \\
\hline 1972 & $\begin{array}{l}63 \text { atletas de Taipei participaram dos Jogos } \\
\text { Olímpicos de Munique. }\end{array}$ \\
\hline 1979 & A China recuperou seu status legítimo no IOC. \\
\hline 1980 & $\begin{array}{l}\text { A China não enviou atletas aos Jogos Olímpicos } \\
\text { de Moscou. }\end{array}$ \\
\hline 1984 & $\begin{array}{l}\text { Um total de } 225 \text { esportistas da China participaram } \\
\text { dos Jogos Olímpicos de Los Angeles. O atirador } \\
\text { Xu Haifeng ganhou a primeira medalha de ouro } \\
\text { desta Olimpíada, que também foi a primeira } \\
\text { medalha de ouro da China na história olímpica. } \\
\text { A China ganhou no evento um total de } 15 \\
\text { medalhas de ouro, } 8 \text { de prata e } 9 \text { de bronze. }\end{array}$ \\
\hline 1988 & $\begin{array}{l}301 \text { esportistas chineses participaram dos } \\
\text { Jogos Olímpicos de Seul, com resultados de } 5 \\
\text { medalhas de ouro, } 11 \text { de prata e } 12 \text { de bronze. }\end{array}$ \\
\hline 1989 & He Zhenliang foi eleito vice-presidente do IOC. \\
\hline 1991 & $\begin{array}{l}\text { Foi estabelecido o Comitê de Beijing para solicitar } \\
\text { o direito de sediar os Jogos Olímpicos } 2000 .\end{array}$ \\
\hline 1992 & $\begin{array}{l}251 \text { atletas chineses participaram dos Jogos } \\
\text { Olímpicos de Barcelona e ganharam } 16 \\
\text { medalhas de ouro, } 22 \text { de prata e } 16 \text { de bronze. }\end{array}$ \\
\hline
\end{tabular}


Ano XXI, n 32/33, junho e dezembro/2009

\begin{tabular}{|c|c|}
\hline Ano & Fato \\
\hline 1996 & $\begin{array}{l}\text { A China enviou uma delegação integrada por } \\
309 \text { atletas aos Jogos Olímpicos de Atlanta e } \\
\text { obteve } 16 \text { medalhas de ouro, } 22 \text { de prata e } 12 \\
\text { de bronze. Além disso, conseguiu estabelecer } 4 \\
\text { novos recordes mundiais nesta olimpíada. }\end{array}$ \\
\hline 1997 & $\begin{array}{l}\text { O presidente do IOC, Antonio Samaranch, } \\
\text { anunciou que Hong Kong participaria da } \\
\text { Olimpíada sob o nome "Hong Kong da China". }\end{array}$ \\
\hline 2000 & $\begin{array}{l}311 \text { atletas chineses participaram dos Jogos } \\
\text { Olímpicos de Sydney e ganharam } 28 \text { medalhas } \\
\text { de ouro, } 16 \text { de prata e } 15 \text { de bronze. }\end{array}$ \\
\hline 2001 & $\begin{array}{l}\text { A China ganhou o direito de sediar os Jogos } \\
\text { Olímpicos } 2008 \text { com } 56 \text { votos a favor. }\end{array}$ \\
\hline 2004 & $\begin{array}{l}\text { A China ganhou um recorde de } 32 \text { medalhas } \\
\text { de ouro, } 17 \text { de prata e } 14 \text { de bronze nos Jogos } \\
\text { Olímpicos de Atenas, superando pela primeira } \\
\text { vez a Rússia (que obteve } 27 \text { ouros) para ocupar o } \\
\text { segundo lugar no quadro de medalhas de ouro, } \\
\text { ficando apenas atrás dos EUA ( } 35 \text { de ouro). }\end{array}$ \\
\hline 2008 & $\begin{array}{l}\text { A China sedia as XXIX Olimpíadas em Beijing. O } \\
\text { país é considerado o campeão geral no quadro } \\
\text { de medalhas, com } 51 \text { de ouro, } 21 \text { de prata e } 28 \\
\text { de bronze, na edição considerada com o maior } \\
\text { investimento até aquele momento. }\end{array}$ \\
\hline
\end{tabular}

Fonte: Adaptado de IOC (2008)

Os impactos para a China a partir da ocorrência das Olimpíadas poderão ser refletidos no futuro em termos de contribuição ao desenvolvimento do país. No entanto, vale um contraponto no que diz respeito aos reais legados deixados para a China após um evento de tamanha magnitude, questionandose até que ponto as Olimpíadas de fato contribuíram para a realidade cotidiana da população?

Pomar (2003) ressalta que a escolha de Beijing como sede para as Olimpíadas intensificou o ritmo de construções no país que já se ob- 
servava na instauração de grandes obras, como a iniciada em 1993 no complexo hidráulico Três Gargantas no rio langtsé, prevista para conclusão em 2009 e que mobiliza um investimento de US\$ 12 bilhões, ou ainda a moderna ferrovia que liga o leste da China a Lhasa, no Tibet, a 4500 metros de altitude. O autor, contudo, enfatiza que está aberto o debate sobre quais são os impactos da modernização em áreas hutongs que agremiam bairros com constru- ções antigas típicas.

A preocupação não reside somente nos hutongs, mas também nas próprias construções que foram estabelecidas na época das antigas dinastias. Com a modernização da cidade, impulsionada pelo crescimento econômico e conseqüente especulação imobiliária, até que ponto o país estaria preparado para garantir o seu conjunto arquitetônico, conciliando com as novas demandas da sociedade globalizada?

\section{FIGURA 1- Fortificação Zhengyang Men, remete à dinastia Qing e hoje utilizada como o Museu de História de Beijing}

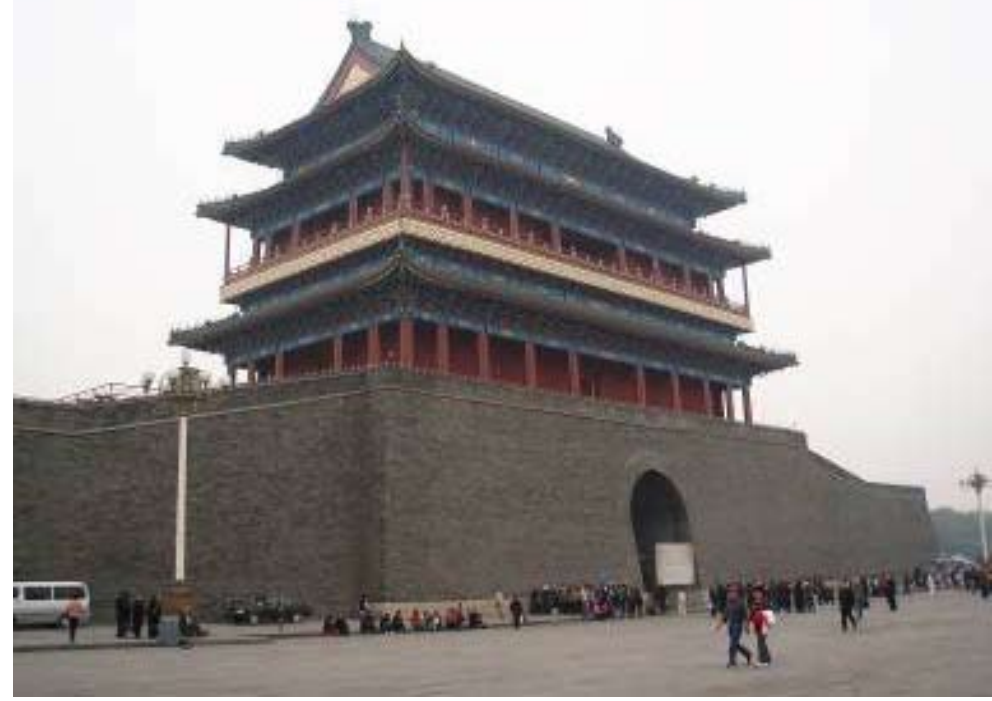

Fonte: Créditos do autor 
Ano XXI, n 32/33, junho e dezembro/2009

Por ocasião do Jogos Olímpicos levou-se a construção de dez mil obras de infraestrutura, como estádios, hotéis, restaurantes, em grande parte a partir de 2001, criando um notório contraste com os templos milinares. No transporte, o metrô recebeu mais de 87 quilômetros de vias, com seis novas linhas. A reforma do aeroporto foi projetada pelo mundialmente renomado arquiteto britânico Norman Foster.

\section{FIGURA 2- Ampliação do metrô em Beijing}

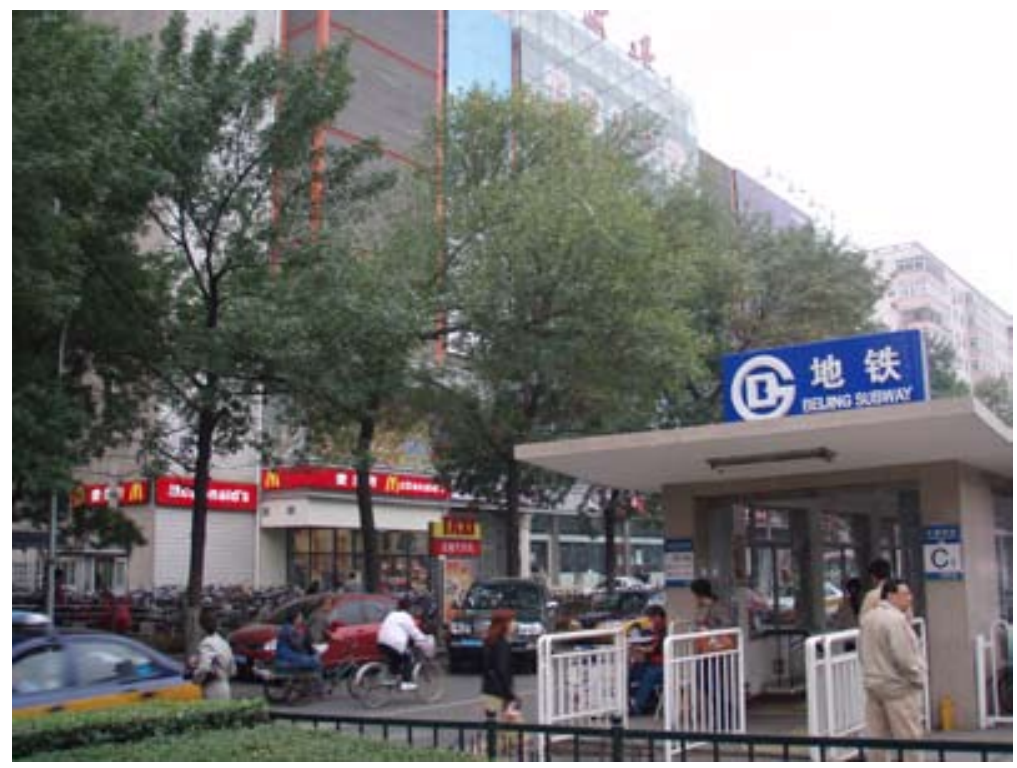

Fonte: Créditos do autor

Ao todo, estima-se que foram gastos em torno de US\$ 42 bilhões de dólares para essa edição dos Jogos, sendo US\$ 40 bilhões para melhorar a infraestrutura da cidade sede e US\$ 2 bilhões para a construção dos equipamentos diretamente relacionados ao evento (ginásios, estádios, arenas), um recorde de investimento que antes era da edição de Sydney em 2000, com US\$ 8 bilhões ${ }^{6}$. Por volta de

6 Artigo publicado na revista Newsweek implica que as construções para as Olimpíadas de Beijiijng são as mais expressivas no mundo desde as reconstruções pós-Segunda Guerra Mundial (LIU, 2007). 
1,2 milhão de operários foram contratados para a construção de dezesseis complexos esportivos, entre eles o "Ninho de Pássaro", ide- alizado pelo escritório suíço Herzog \& DeMeuron e que foi o estádio de abertura e encerramento do evento (BOCOG, 2008):

\section{FIGURA 3- Construção do estádio "Ninho do Pássaro" em Beijing}

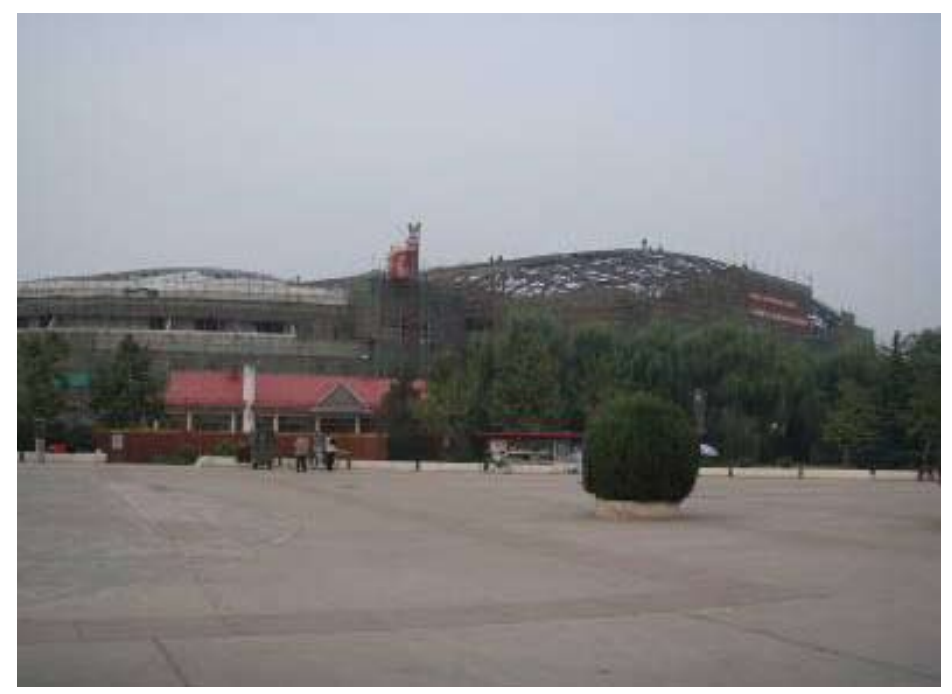

Fonte: Créditos do autor

Importante mencionar que nem toda a verba investida na realização do evento vinha do próprio governo e dos patrocinadores. O Centro Aquático Nacional, conhecido como "Cubo D 'Água", custou por volta de U\$150 milhões e foi financiado em sua expressiva parte com doações de mais de 350 mil chineses emigrados em todo o mundo. Aos doadores, a garantia que seriam gravados seus nomes no jardim ao lado do Centro (BOCOG, 2008).

Além dos expressivos gastos envolvidos em infraestrutura, a ocorrência dos Jogos Olímpicos trouxe uma ampla gama de alterações de várias ordens no contexto sociocultural vivido pela população até então, mudanças essas manifestadas na especulação imobiliária, nas políticas de preservação 
Ano XXI, n 32/33, junho e dezembro/2009

ambiental, entre outras variáveis atingidas direta ou indiretamente pelo mega evento ${ }^{7}$.

Nesse sentido, foi promovido uma verdadeira "campanha civilizatória" para receber o ocidente, revestida de uma certa "Educação Olímpica" a ser realizada para o povo chinês visando a realização das Olimpíadas. Veremos a seguir elementos associados a esse contexto.

\section{Uma "campanha civilizatória" em marcha por ocasião das Olimpíadas da China}

Se algumas alterações já vinham sendo pregadas há um certo tempo no país com a abertura para o ocidente ${ }^{8}$, após a oficialização da candidatura da China às Olimpíadas um certo ajuste deveria ser realizado para o grande evento.

No entendimento dos realizadores dos Jogos, um fato a ser trabalhado seria modificar certos costumes da cultura chinesa que poderiam parecer um tanto estranhos aos turistas ocidentais. Instaurou-se assim uma campanha de boas ma- neiras que envolvia várias práticas, numa espécie de "Educação Olímpica" sem precedentes.

$\mathrm{O}$ ato de cuspir, por exemplo, comum ao povo chinês, passou a ser considerado uma ofensa passível de multa. Placas foram espalhadas pelas grandes cidades do país, procurando "educar" a sociedade sobre a necessidade de evitar tal prática, como vemos na figura a seguir.

\section{FIGURA 4- Placa de "probido cuspir" na China}

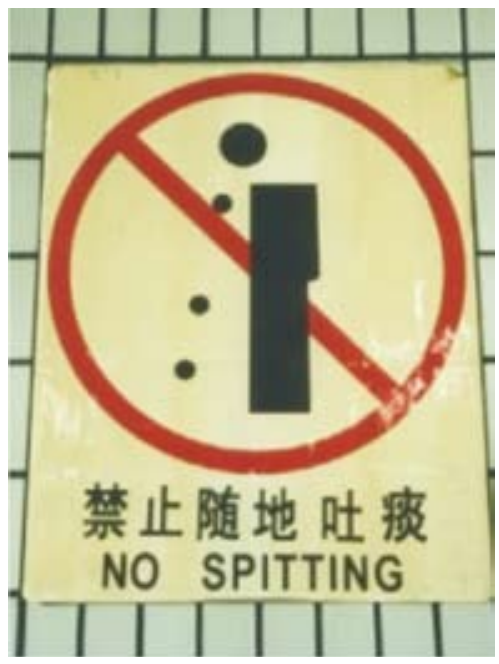

Fonte: Adaptado de Flumesday (2006)

7 Texto publicado na Revista Veja menciona que, por ocasião dos Jogos Olímpicos e em nome da mordernização, o Governo chinês transferiu 300 mil famílias de Beijijng para outras regiões do país. Entretanto, alguns moradores mostraram resistência e foram motivo de retaliação pela maioria da população que apoiava o evento e retiradas de seus lares originais a partir das medidas restritivas governamentais (OYAMA, 2008).

8 O sinal vermelho significava ir à frente, na época de Mao, por ser a cor do comunismo. Com a abertura, teve-se que readequar tal situação a padrões internacionais. 
Outras práticas, como o arroto em público, também deveriam ser evitadas. Leite (1999) lembra que o arroto na China expressa um sinal de satisfação, pouco comum na sociedade ocidental. Segundo o autor, o ato foi amplamente relatado por ocidentais que estiveram naquele país como sendo um elemento "desagradável", "glutão", "esfaima$\mathrm{do}^{\prime} \mathrm{e}$ "mal-educado à mesa".

A lista elaborada pelo governo chinês para os Jogos envolvia ainda: não jogar lixo no chão; não pendurar roupas nas sacadas; não usar pijamas em público; não furar filas; comer silenciosamente; não falar alto; evitar sair de casa para dar mais espaço aos turistas na cidade; não incomodar os turistas com perguntas sobre idade, estado civil, saúde, família, religião, opiniões políticas ou vida amorosa (GOOD MANNERS..., 2007).
Shaw (2006) aponta que o sucesso na implementação de projetos e políticas de lazer, tanto locais como globais, dependerá do claro entendimento de suas implicações atreladas ao cotidiano do cidadão numa dada cultura. Questiona-se até que ponto o cidadão chinês estaria de fato disposto a contribuir com toda essa mudança de hábitos, rumo à uma mencionada "Educação Olímpica"?

Acresce-se às boas maneiras o fato do país ter que se adequar a uma sinalização turística padronizada internacionalmente, aplicável aos meios de transporte e na referência a museus, parques, praças, entre outros. Sobre tal ponto, foi possível verificar mesmo em grandes cidades, como Shanghai, que a sinalização com o descritivo de horários e linhas de ônibus trazia somente a informação em chinês, praticamente nada esclarecedora para um turista ocidental:

FIGURA 5 - Timetable em ponto de ônibus na cidade de Shanghai

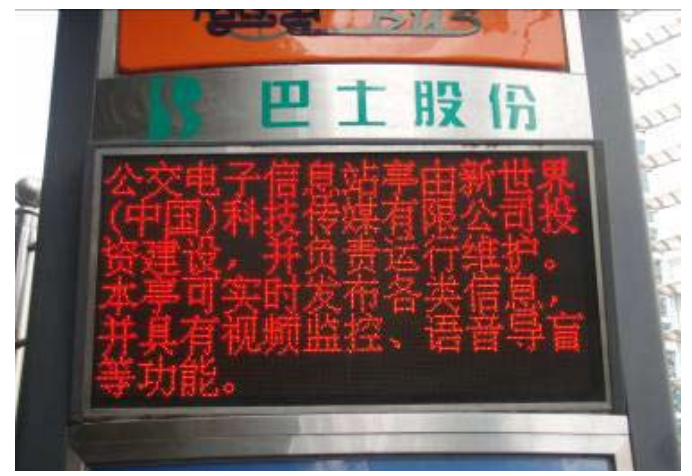

Fonte: Créditos do autor 
Ano XXI, n 32/33, junho e dezembro/2009

Importante também era se aproximar do idioma inglês, para procurar a melhor comunicação com o turista, em especial o ocidental. Constatou-se que poucas pessoas falavam o idioma, restrito a jovens estudantes ou aqueles que trabalhavam com turismo. $\mathrm{O}$ peculiar chinglish (Chinese + English) era constantemente motivo de piadas em vários websites ${ }^{9}$.

Aulas do idioma na TV estatal começaram a ser lecionadas logo após o anúncio de que Beijing sediaria as Olimpíadas. O governo municipal lançou em 2002 o Beijing Speaks Foreign Languages Program (BSFLP), com o objetivo de melhorar o nível do idioma inglês dos residentes da cidade e melhorar a tradução nos cardápios de restaurantes. Foram instituídas algumas ações pelo BSFLP, como: o Beijijng English Test System, uma certificação em três níveis no idioma inglês aberto a todo cidadão; encontros em língua inglesa em esquinas da cidade; festivais de inglês em parques; incentivo a competições de habilidade na língua inglesa; exposição de filmes ocidentais sem legenda.
Foram ainda contratados especialistas dos EUA, Grã Bretanha e Cingapura. O BSFLP foi compreendido como vital no sentido de melhorar a sinalização turística, bem como identificar de forma mais apropriada consultórios médicos, escritórios. Durante as olimpíadas, as ações pelo BSFLP foram destinadas a auxiliar o turista estrangeiro, mesmo aqueles que não conseguiam falar o inglês, dispondo de uma linha telefônica de consulta gratuita em nove idiomas. Segundo dados do Programa, quase 5 milhões de pessoas estariam habilitadas a falar o inglês em Beijing em diferentes níveis (BSFLP, 2007).

Outra intempérie evidente era a poluição da cidade de Beijing, sede de grande parte dos jogos. Apesar da China ser considerada hoje a líder mundial na produção de energia renovável ${ }^{10}$, a poluição do ar se mostrou um grave problema na cidade que sediaria os Jogos Olímpicos.

A frota de carros na cidade ultrapassa 3,5 milhões de veículos e rivaliza com as bicicletas e riquixas. Para reduzir a poluição, foi

9 Artigo no China Daily identificou alguns dos erros mais comuns no chinglish. Ao tentar traduzir uma frase do chinês para o inglês "ao pé da letra", trazia-se em cardápios bilíngües pratos como young chicken without sex (frango jovem sem sexo) ou husband and wife lung slice (fatia de pulmão de marido e mulher) por conta da gramática chinesa não fazer distinção entre os gêneros masculino e feminino (CHINGLISH..., 2007).

10 Segundo dados do The Climate Group, a China é um exemplo para o mundo em termos de desenvolvimento de tecnologias de baixo carbono. A instituição sugere que o país está passando atualmente por uma "Revolução Limpa" (THE CLIMATE..., 2008). 
implantado um rigoroso esquema de rodízio por placas, a exemplo do que acontece na cidade de São Paulo, evitando que circulassem dois milhões de carros/dia. Também foram plantadas mais de duas bilhões de árvores no ano de 2007, assim como mais de 150 fábricas tiveram que parar sua linha de produção para tentar minimizar a emissão de poluentes (XINHUA, 2008).

Em termos de competição, a poluição pode sugerir uma boa condição para os atiradores pelo contraste da cor do disco com a névoa branca, mas era definitivamente ruim para maratonistas, ciclistas, triatletas e remadores ${ }^{11}$.

Uma outra situação inconveniente para o governo chinês envolveu a passagem da tocha olímpica por vários pontos do mundo. Símbolo do pré-evento, virou alvo de manifestações nos EUA e Europa. Boa parte das reivindicações manifestadas se referia à falta de liberdade na China e, em especial, eram solidárias à causa do Tibet.

$O$ valor do Tibet para a China é notório. Além de uma expressiva fonte de água para o país é também uma zona estratégica com relação à Índia e Nepal. Ganhou status de região autônoma da China em 1965 e desde então é considerada uma zona de conflito entre simpatizantes de Tenzin Gyatso, o atual Dalai Lama12 ${ }^{12}$ (EYEWITNESS..., 2005).

Mesmo durante os Jogos e sob forte esquema policial, foram observados atentados no país, tanto na capital como em outros estados. Dois atentados ocorreram em Xinjiang, local de maioria uigur. Em Beijijng, a Drum Tower, famoso ponto turístico local, foi palco do assassinato de um turista norte-americano no primeiro dia dos Jogos.

Aqueles que criticaram abertamente o sistema foram presos ou afastados dos holofotes da mídia. Segundo informações do Human Rights Watch (HRW), a ativista Ni Yulan foi presa em 2002 por tentar ajudar os moradores removidos de suas casas por ocasião do cronograma de modernização imposto para os Jogos. Yualan vinha sendo um dos ícones em termos de protestos de ativistas por todo o mundo e, entre outros, filmou a demolição de uma residência em Beijijng, tendo sua prisão decretada na seqüência (HRW, 2008).

A internet sofreu vários tipos de censura no período préevento e o governo foi acusado pelo

11 A equipe de ciclismo norte-americana protestou veementemente e desembarcou usando máscaras no aeroporto da capital.

12 Prêmio nobel da paz em 1989, mesmo ano do massacre na Praça Tiananmen, Tenzin Gyatso vive atualmente na cidade de Dharamsala na Índia. 
Ano XXI, n 32/33, junho e dezembro/2009

ocidente de manipular informações a partir de suas agências estatais, procurando criar um clima amistoso e de apoio massivo do povo chinês às alterações necessárias no cotidiano para um bom desenvolvimento dos Jogos.

Entende-se fundamental destacar um relevante ponto: além de se preparar arduamente e sediar o evento de forma grandiosa, tornou-se um projeto maior ganhar os Jogos ${ }^{13}$, derrotando os principais adversários, EUA e Reino Unido, e provando para o mundo uma superioridade não somente econômica, mas também esportiva.

Nesse sentido, vale mencionar o Project 119, organizado pelo General Administration of Sport China (GASC), que foi deflagrado no ano de 2000 pelo Governo Federal posterior à participação da China nas Olimpíadas de Sydney. Recebeu esse nome devido ao fato do país, em toda sua história de participação nos Jogos Olímpicos, conquistar apenas 119 medalhas em modalidades em que o país era "fraco" ou "sem tradição": natação, atletismo, vela, remo e canoagem.

Após o anúncio do país como sede dos Jogos Olímpicos em 2001, o projeto foi intensificado recebendo considerável aporte financeiro com o objetivo maior de conquistar medalhas nas mencionadas modalidades. Técnicos estrangeiros foram contratados e atletas do país incentivados a ganhar experiência em ligas internacionais em outros países. Um grande número de escolas, em especial nas zonas rurais, recebeu incentivo para treinamento esportivo, em que talentos nas referidas modalidades foram surgindo a partir desse trabaIho (GASC, 2008).

Os resultados já surtiram efeito nos Jogos Olímpicos de Atenas 2004: a China foi vice-líder no quadro de medalhas daquele ano, com 32 medalhas de ouro, sendo 23 delas oriundas de apenas seis modalidades: badminton, ginástica, judô, levantamento de peso, saltos ornamentais e tênis de mesa.

Segundo informações a partir do Beijiing Organizing Committe for the Olympic Games - BOCOG, o governo chinês é o que tem maior orçamento para o fomento da prática esportiva no mundo atualmente. Os atletas profissionais chineses devem dividir parte do que ganham com o governo, no entendimento da reciprocidade por ter sido

13 Para análise de que país sai vencedor dos Jogos, leva-se em conta o total de medalhas de ouro conquistadas, independente do número de pódios alcançados. Em 26 edições dos Jogos, os EUA ganharam em 15 (IOC, 2008). 
patrocinado pelo Estado (BOCOG, 2008) $)^{14}$.

É provável que a medalha de ouro em 2004 com mais significado para legitimar o projeto 119 foi a conquistada por Liu Xiang, na prova de 110 metros com barreiras. Isso porque a China não tinha até então qualquer tradição na prova de atletismo, ainda mais nessa prova que exige um considerável uso de força, e Liu passaria a ser um ídolo do esporte chinês ${ }^{15}$.

Tanto o ouro conquistado por Liu Xiang numa prova de força no atletismo como o próprio Projeto 119 fomentado pelo GASC sugerem um certo sentimento de inferioridade do povo chinês pelo possível sentimento de fraqueza e inaptidão em termos de força com relação ao seu próprio corpo.

Por diversas vezes, foi possível encontrar na mídia do país que uma vitória geral nas Olimpíadas de Beijing auxiliaria na minimização do sentimento histórico de ser o chinês um "Homem Doente da Ásia", termo esse que remonta ao império Qing no final do século 19 e início do século 20 em que o Japão e o Ocidente forçaram a China a fazer concessões, denotando um povo fraco militarmente e pouco desenvolvido economicamente ${ }^{16}$.

Pode-se inferir assim que os Jogos significavam para o povo chinês uma oportunidade de identificação de sua cultura para o mundo, em especial para ocidente, expressando força na vitória e expressividade de seu coletivo, mesmo com as notórias intempéries verificadas no país como censura, pobreza e desigualdade social.

Como preparação para 2008, a imagem dos cinco mascotes foram veiculadas com notória expressividade em todo o mundo ${ }^{17}$. Foram eles: Beibei (o peixe), Jingjing (o panda), Huanhuan (a chama olímpica), Yingying (o antílope tibetano) e Nini (a andorinha).

14 Ao contrário da China, os EUA tem o investimento no esporte de alto nível a partir do setor privado. Os patrocinadores têm suas marcas expostas, entre outros, no website da entidade que é responsável pelos esportes olímpicos, a United States Olympic Committee - USOC.

15 Nas Olimpíadas de 2008, a esperança de Liu por uma nova medalha foi interrompida por causa de uma lesão no tendão-de-aquiles, que o fez abandonar a prova.

16 Segundo artigo de David Ting no The China Post (TING, 2008), o termo Sick Man of Asia aproxima-se de Sick Man of Europe, em alusão ao enfraquecimento do Império Otomano. Foi novamente utilizada na Segunda Guerra Mundial, com o predomínio do Japão em territórios chineses.

17 De acordo com informação no website oficial das Olimpíadas, as primeiras sílabas dos mascotes formam a frase Beijing Huanyíng Ni ou "Beijing dá boas vindas a você" (BEIJING 2008..., 2007). 
Ano XXI, $n^{\circ} 32 / 33$, junho e dezembro/2009

\section{FIGURA 6- Mascotes Yingying e Nini na Praça Tiananmen em Beijijng}

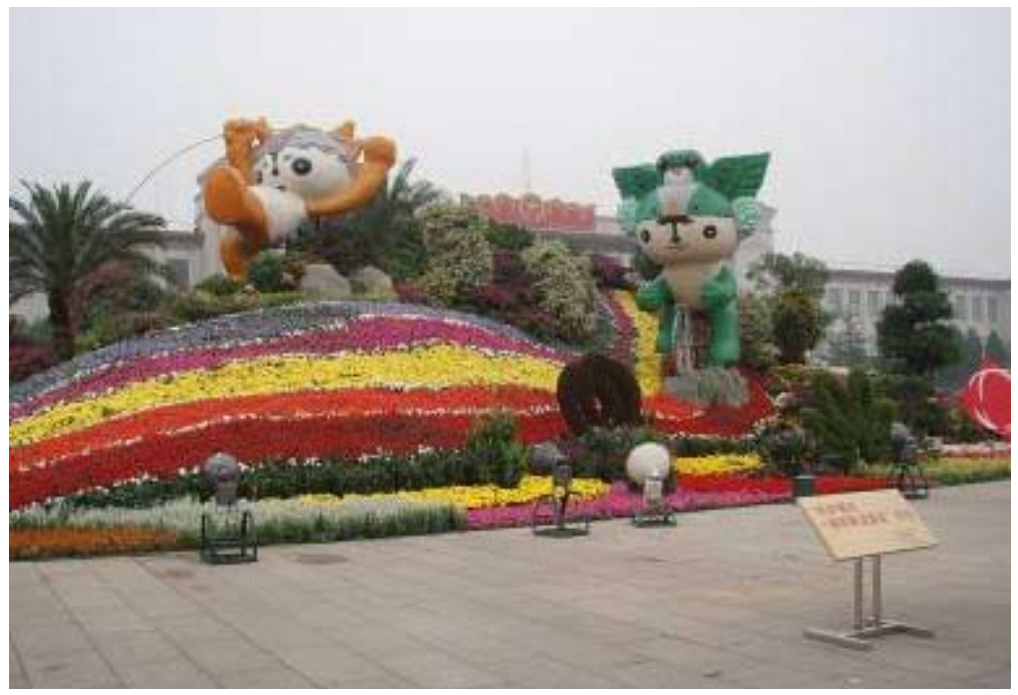

Fonte: Créditos do autor

Aos mascotes também foram atribuídos o significado de fuwa (benção) representando: Beibei (água-prosperidade), Jingjing (madeira-felicidade), Huanhuan (fogo-paixão), Yingying (terra-saúde) e Nini (metal-boa sorte) (BEIJING 2008..., 2007).

A Olimpíada ocorreu sob o signo do número 8 . O evento teve início no dia 08/08/2008 às 8h08 p.m em Beijing ${ }^{18}$. A abertura da Olimpíada ocorreu no ginásio "Ninho de Pássaro" para 91 mil espectadores. A programação incluiu invenções da China antiga, do papel a pipa, do relógio de sol ao alfabeto chinês, da pólvora até a ida do astronauta ao espaço.

O presidente $\mathrm{Hu}$ Jintao e o premiê Wen Jiabao foram identificados pelas imagens da TV por várias

18 A explicação para o significado do número 8 para o povo chinês reside no fato de que seu som se assemelha a palavra prosperidade, riqueza. Em contrapartida, o número 4 é considerado de azar para o chinês, já que seu som tem a proximidade com a palavra morte, sendo comum não se encontrar o quarto andar na China, até mesmo na capital. O dia 08/08/2008 também significou uma data especial para casamentos no país: estima-se que somente em Beijing foram celebrados mais de doze mil cerimônias, mobilizando uma operação especial por parte do Governo para atender tal demanda (XINHUA, 2008). 
ocasiões. Entre os oitenta chefes de Estado presentes, estavam Luiz Inácio Lula da Silva, Nicolas Sarkozy e George W. Bush, primeiro presidente americano em uma abertura de Jogos no exterior.

Segundo informações a partir do BOCOG, o espetáculo envolveu trinta mil fogos de artifícios, luzes e telões de alta definição e o desfile de duzentas e quatro delegações de atletas, técnicos e dirigentes. O atleta Yao Ming ${ }^{19}$ carregou a bandeira, junto com Lin Hao, de 9 anos, sobrevivente do terremoto de Sichuan. Estavam presentes as cinqüenta e seis etnias chinesas (BOCOG, 2008).

Duas mil e oito pessoas tocaram tambor simultaneamente para a contagem regressiva num início de evento visto por mais de quatro bilhões de pessoas pela TV. Li Ning, ginasta que ganhou três medalhas de ouro na Olimpíada de 1984, acendeu a pira olímpica. "Caminhou" pela borda da cobertura, em que projeções mostravam a tocha pelo mundo, sem os protestos ocorridos em Londres, Paris e San Francisco.

A cerimônia de abertura no entanto deixou de abordar a decadência, a pobreza e o período de turbulência do século XIX até a abertura econômica de Deng Xiaoping. Não houve menção à Revolução Chinesa, à Revolução Cultural ou ainda a Mao Tse-tung.

Os Jogos ocorreram em trinta e sete sedes, com apenas três delas foras de Beijijng ${ }^{20}$. Além dos investimentos recordes já citados, recebeu o maior número de países participantes das Olimpíadas com o maior número de atletas: 205 países, 10.5 mil atletas.

O encerramento das Olimpíadas apresentou uma magnitude como se viu na abertura, com shows pirotécnicos por toda a cidade, apresentações no "Ninho de Pássaro" e aparição na mídia mundial de políticos chineses e do IOC.

Os Jogos sinalizaram no cômputo final a supremacia da China no quadro geral de medalhas. Foram ao todo 51 de ouro, 21 de prata e 28 de bronze, perfazendo uma condição inédita na história dos Jogos atingindo um dos objetivos que era de vitória frente à $E U A^{21}$ e Europa. O Brasil ficou em $23^{\circ}$. lugar, com 3 medalhas de ouro, 4 de prata e 8 de bronze.

19 Atleta de basquetebol, famoso por jogar a liga profissional norte-americana.

20 Exceto pela competição de vela, ocorrida em Qingdao, do hipismo em Hong Kong e de algumas partidas do futebol, disputadas em Qinhuangdao, Shaghai e Shenyang.

21 Os EUA ficaram em segundo lugar na classificação geral, 36 de ouro, 38 de prata e 36 de bronze. Foram derrotados em modalidades que até então tinham prelazia, como o atletismo e ginástica, e ameaçavam entrar com representação no IOC contra a China por adulteração na idade das ginastas daquele país, pela suspeita de atletas que competiram com menos de 16 anos. 
Ano XXI, n 32/33, junho e dezembro/2009

Wenge (2006) defende que a ocorrência das Olimpíadas na China deveria ser seguida de uma reforma curricular no ensino superior do país em cursos como Educação Física e Turismo, a exemplo do que aconteceu em boa parte de países que já tiveram a oportunidade de sediar um evento com tal magnitude.

O fato é que o evento mobilizou diretamente a educação do país. Entre os programas relacionados, talvez um dos mais expressivos seja o Heart-to-heart, lançado em dezembro de 2006 como um componente do programa de educação para os Jogos. Teve o objetivo de envolver alunos de escolas de Beijing para torcer por um país participante do evento e ter contato com o idioma, a cultura, a história, a geografia, os costumes, a etiqueta do mesmo (BOCOG, 2006).

\section{Conclusão}

Pode-se inferir que os Jogos significaram para o povo chinês uma oportunidade de identificação de sua cultura para o mundo, em especial para ocidente, expressando força na vitória, contestação da sua suposta fraqueza e expressividade de seu coletivo. O projeto esportivo maior de ganhar os Jogos Olímpicos "em casa", derrotando os principais adversários norteamericanos e europeus foi atingido, provando para o mundo uma superioridade não somente econômica, mas também esportiva.

Contudo, questiona-se se o desenvolvimento no campo comercial e econômico contribuiu de fato com a melhoria das condições da população? A imagem de uma Olimpíada bem organizada e com o maior orçamento de todos os tempos contrasta com um país que ainda reluta com índices de pobreza e desigualdade social.

O fato é que os Jogos Olímpicos trouxeram uma ampla gama de alterações de várias ordens no contexto sociocultural vivido pela população até então, em que se destacam as campanhas civilizatórias para receber o ocidente a partir de uma certa "Educação Olímpica". Entende-se que uma análise sobre tal evento não deve desprezar, de forma criteriosa, o impacto desse megaevento na realidade chinesa, analisando os impactos positivos e negativos do mesmo para a realidade cotidiana da população local.

Com base nessa experiência, entende-se fundamental analisar os atuais preparativos para os dois megaeventos a serem realizados em território brasileiro: Copa do Mundo 2014 e Olimpíadas 2016. Pesquisas de opinião realizadas até meados 
do ano de $2010^{22}$ indicam que $57 \%$ da população brasileira condenam o uso de verba pública para a realização da Copa, frente aos $\mathrm{R}$ \$ 5,1 bilhões que devem ser gastos nos estádios (valor $168 \%$ maior em relação ao que a Confederação Brasileira de Futebol apontava na candidatura como aporte necessário para o evento).

Os estudos acadêmicos temáticos devem dar conta de avaliar os prós e contras dos megaeventos esportivos no Brasil, servindo como relevante elemento para auxiliar na condução de uma política transparente por parte dos Comitês Organizacionais. Faz-se mister assim levar em consideração o valioso exemplo ocorrido na cultura chinesa, mesmo que se trate de uma realidade aparentemente tão dispare da brasileira mesmo em dias que vivemos sob a égide da globalização.

\section{REFERÊNCIAS}

BEIJING 2008. The official website of the Beijing 2008 Olympic Games - Games of the XXIX Olympiad. The official mascots of the Beijing 2008 Olympic Games. Disponível em: < http:// en.beijing2008.cn > . Acesso em: 14 abr. 2007.

BOCOG. Beijiing Organizing Committe for the Olympic Games. BOCOG launches Heart to Heart Partnership Program of Beijing Olympics. 2006. Disponível em: $<$ http://english.cri.cn $>$. Acesso em: 23 fev. 2007.

BOCOG. Beijiing Organizing Committe for the Olympic Games. Special reports. Disponível em: < http:// en.beijing2008.cn/bocog > . Acesso em: 09 ago. 2008.

BSFLP. Beijing Speaks Foreign Languages Program. Disponível em: < http://bjenglish.bjfao.gov. cn>. Aceso em: 20 jun. 2007.

CHINGLISH on Beijing's signs shocks foreigners. China Daily. Disponível em: <www. chinadaily.com.cn $>$. Acesso em: 17 jun. 2007.

EYEWITNESS Travel Guides. China. London: Dorling Kindersley Ldt, 2005.

FLUMESDAY.COM. China tells tourists 'stop spitting'. Disponível em: < www. flumesday.com $>$. Acesso em: 20 nov. 2006.

GASC. General Administration of Sport China. Disponível em: <www. china.org.cn/english/government $>$. Acesso em: 28 jul. 2008. 
Ano XXI, n 32/33, junho e dezembro/2009

GOOD MANNERS Campaign goes National. China. org. Disponível em: <www.china.org.cn>. Acesso em: 20 fev. 2007.

HRW. Human Rights Watch. China: beaten activist to be tried on eve of Olympics. Disponível em: $<$ www.hrw.org > . Acesso em: 11 ago. 2008.

IOC. International Olympic Committee. Olympic Games. Disponível em: $<$ www.olympic.org.uk>. Acesso em: 20 jul. 2008.

LEITE, J. R. T. A China no Brasil: influências, marcas, ecos e sobrevivências chinesas na sociedade e na arte brasileiras. Campinas, SP: UNICAMP, 1999. LIU, M. World affairs: Beijing reborn. Newsweek, New York, USA, 13 ago. 2007.

MORRIS, A. D. Marrow of the nation: a history of sport and physical culture in Republican China. Berkeley, USA: University of California Press, 2004.

OYAMA, T. A nova revolução cultural. Revista Veja, São Paulo, Abril, 6 ago. 2008. p. 136-143.

PESQUISA: brasileiros condenam dinheiro público na Copa; Morumbi é favorito. Disponível em: < http://esporte.uol.com. br $>$. Acesso em: 16 ago. 2010. POMAR, W. A revolução chinesa. São Paulo: Editora UNESP, 2003.

SHAW, S. M. Re-framing questions: assessing the significance of leisure. In: JACKSON, E. L. (Ed.) Leisure and the quality of life: impacts on social, economic and cultural development - Hangzhou Consensus. Hangzhou, China: Zhejiang University Press, 2006. p. 40-46.

THE CLIMATE Group. China unleashes clean revolution. Disponível em: < www. theclimategroup.org $>$. Acesso em: 31 jul. 2008.

TING, D. From Asia's 'sick man` to strongman. The China Post. Disponível em: <www. chinapost.com.tw $>$. Acesso em: 03 jul. 2008.

UVINHA, R. R. Lazer numa perspectiva internacional: relações temáticas com o turismo, os esportes e a educação na China atual. 2008. Tese (Livre-docência), Escola de Artes, Ciências e Humanidades, Universidade de São Paulo. São Paulo, USP, 2008. 144 p.

XINHUA. China news. Disponível em: <www.xinhuanet.com > . Acesso em: 09 ago. 2008.

WENG, P. Study on Physical Education, Tourism Education and the curriculum in colleges and universities in and outside China. In: WORLD LEISURE CONGRESS, 9., 2006, Hanghzou. Proceedings... Hanghzou, China: WLRA, 2006.

Recebido: Julho/2010 Aprovado: Agosto/2010 